\title{
Video Article \\ Preparing E18 Cortical Rat Neurons for Compartmentalization in a Microfluidic Device
}

\author{
Joseph Harris ${ }^{1}$, Hyuna Lee ${ }^{1}$, Christina Tu Tu ${ }^{2}$, David Cribbs ${ }^{3}$, Carl Cotman ${ }^{3}$, Noo Li Jeon ${ }^{1}$ \\ ${ }^{1}$ Department of Biomedical Engineering, University of California, Irvine (UCl) \\ ${ }^{2}$ Stem Cell Research Center, University of California, Irvine (UCI) \\ ${ }^{3}$ Institute for Brain Aging and Dementia, University of California, Irvine (UCI)
}

Correspondence to: Joseph Harris at jwharris7@gmail.com, Noo Li Jeon at njeon@uci.edu

URL: https://www.jove.com/video/305

DOI: doi:10.3791/305

Keywords: Neuroscience, Issue 8, Biomedical Engineering, Neurons, Axons, Axonal Regeneration, Neuronal Culture, Cell Culture

Date Published: 10/1/2007

Citation: Harris, J., Lee, H., Tu, C.T., Cribbs, D., Cotman, C., Jeon, N.L. Preparing E18 Cortical Rat Neurons for Compartmentalization in a Microfluidic Device. J. Vis. Exp. (8), e305, doi:10.3791/305 (2007).

\section{Abstract}

In this video, we demonstrate the preparation of E18 cortical rat neurons. E18 cortical rat neurons are obtained from E18 fetal rat cortex previously dissected and prepared. The E18 cortex is, upon dissection, immediately dissociated into individual neurons. It is possible to store E18 cortex in Hibernate E buffer containing B27 at $4^{\circ} \mathrm{C}$ for up to a week before the dissociation is performed. However, there will be a drop in cell viability. Typically we obtain our E18 Cortex fresh. It is transported to the lab in ice cold Calcium free Magnesium free dissection buffer (CMFM). Upon arrival, trypsin is added to the cortex to a final concentration of $0.125 \%$. The cortex is then incubated at $37^{\circ} \mathrm{C}$ for 8 minutes. DMEM containing $10 \%$ FBS is added to the cortex to stop the reaction. The cortex is then centrifuged at 2500 rpm for 2 minutes. The supernatant is removed and $2 \mathrm{ml}$ of Neural Basal Media (NBM) containing 2\% B27 (vol/vol) and 0.25\% Glutamax (vol/vol) is added to the cortex which is then re-suspended by pipetting up and down. Next, the cortex is triturated with previously fire polished glass pipettes, each with a successive smaller opening. After triturating, the cortex is once again centrifuged at $2500 \mathrm{rpm}$ for 2 minutes. The supernatant is then removed and the cortex pellet re-suspended with $2 \mathrm{ml}$ of NBM containing B27 and Glutamax. The cell suspension is then passed through a 40 um nylon cell strainer. Next the cells are counted. The neurons are now ready for loading into the neuron microfluidic device.

\section{Video Link}

The video component of this article can be found at https://www.jove.com/video/305/

\section{Protocol}

\section{Preparing E18 Fetal Rat Cortical Neurons for Compartmentalization}

Before starting out, it is important to warm all necessary media and reagents to $37^{\circ} \mathrm{C}$.

It is also important to sterilize everything that is used for preparing the cells (e.g., rubber bulbs, tube racks, media bottles, etc.), and that which is placed in the hood, by wiping down with $70 \%$ ethanol.

1. Place two pieces of E18 Fetal Rat Cortex (one brain, previously dissected) in a $15 \mathrm{ml}$ tube containing $1 \mathrm{ml}$ ice-cold Calcium-free Magnesiumfree dissection buffer.

2. Add $1 \mathrm{ml}$ of $0.25 \%$ Trypsin-EDTA to the cortex in dissection buffer, bringing the final volume to $2 \mathrm{ml}$ and final trypsin concentration to $0.125 \%$.

3. Place the $15 \mathrm{ml}$ tube in a $37^{\circ} \mathrm{C}$ water bath for 8 minutes.

4. During this time, fire polish 3 glass Pasteur pipets, forming successively smaller openings, in a biosafety cabinet to help maintain sterility.

5. After the 8 minute incubation of the cortex, add $10 \mathrm{ml}$ of DMEM containing $10 \%$ FBS to the cortex to help stop the trypsin reaction.

6. Centrifuge the $15 \mathrm{ml}$ tube containing the cortex and DMEM/10\% FBS at $2500 \mathrm{rpm}$ for 2 minutes.

7. In the biosafety cabinet, remove the supernatant from the cortex using a glass Pasteur pipet with vacuum suction attached. Be careful not to disturb or dislodge the pellet.

8. Add $1 \mathrm{ml}$ of NMB to the cortex pellet and gently pipet up and down. It is very important to avoid creating air bubbles while pipeting up and down, as the air bubbles can damage the cells by oxidation.

9. Use the fire-polished Pasteur pipet with the widest opening to triturate the cortex by attaching a sterile rubber bulb to the end and pipeting up and down 5 times, again being careful not to introduce air bubbles. Continue this process with the other 2 glass pipets, each with a decreased opening size.

10. After trituration, centrifuge down the cells again at $2500 \mathrm{rpm}$ for 2 minutes.

11. After centrifugation, once again remove the supernatant and resuspend the cell pellet in $2 \mathrm{ml}$ of NBM.

12. Filter the resuspended cell solution through a 45 um cell strainer. 
13. Stain the cells with Trypan Blue, counted, and loaded into the devices. We typically load 20 ul of cells per device.

Note: the final concentration of cells is typically between 2.5 million cells $/ \mathrm{ml}$ and 8 million cells $/ \mathrm{ml}$

\section{Loading the cells}

After the cells have been counted, it is time to load the cells in the device:

1. Bring the previously prepared devices containing NBM into the biosafety cabinet to maintain sterility.

2. Remove excess media from the wells by vacuum suction. However, be careful to avoid removing all of the media -- there must be some media in the main channel.

3. Apply $20 \mathrm{ul}$ of cells to the top left hand reservoir of the device (see diagram if necessary). The cells flow into the device and attach to the PLL treated surface.

4. After loading, place the devices containing cells back in an incubator for 10 minutes to allow the cells to attach.

5. After 10 minutes, fill the reservoirs with media and place devices back in the incubator.

\section{Discussion}

Cell densities can be varied depending on the application. However, seeding primary neurons at too low of a density typically leads to cell death. Depending on the incubator and the level of humidity, media may need to be changed in the devices every 2 to 3 days. When changing media, it is important after removing the media from the reservoirs, to never remove media from the main channels. Further, it is good practice to place fresh media in the top wells and allow some fresh media to flow through the device and into the main channels before filling up all the reservoirs.

\section{References}

1. Park, J.W., Vahidi, B., Taylor, A.M., Rhee, S.W., Jeon, N.L. Microfluidic culture platform for neuroscience research. Nat Protoc. 2006;1(4):2128-36.

2. Taylor, A.M., Blurton-Jones, M., Rhee, S.W., Cribbs, D.H., Cotman, C.W., Jeon, N.L. A microfluidic culture platform for CNS axonal injury, regeneration and transport. Nat Methods. 2005 Aug;2(8):599-605. 